OPEN ACCESS

Edited by:

Xiao Wang,

Johns Hopkins Medicine,

United States

Reviewed by:

Xiaolei Zhang,

The Second Affiliated Hospital and Yuying Children's Hospital of Wenzhou

Medical University, China Tiziana Anelli,

Vita-Salute San Raffaele University,

Ruoxian Deng

Johns Hopkins University,

United States

*Correspondence:

Zhuojing Luo

ziluo@fmmu.edu.cn

Liu Yang

yangliu@fmmu.edu.cn

Specialty section:

This article was submitted to Molecular and Cellular Pathology,

a section of the journal

Frontiers in Cell and Developmental

Biology

Received: 20 November 2021

Accepted: 24 December 2021

Published: 01 February 2022

Citation:

Wang $D$, He X, Zheng C, Wang C, Peng $P$, Gao C, Xu X, Ma Y, Liu M,

Yang $L$ and $L$ uo $Z$ (2022) Endoplasmic

Reticulum Stress: An Emerging

Therapeutic Target for Intervertebral

Disc Degeneration.

Front. Cell Dev. Biol. 9:819139.

doi: 10.3389/fcell.2021.819139

\section{Endoplasmic Reticulum Stress: An Emerging Therapeutic Target for Intervertebral Disc Degeneration}

\author{
Dong Wang ${ }^{1}$, Xin $\mathrm{He}^{2}$, Chao Zheng ${ }^{1}$, Chengzhe Wang ${ }^{3}$, Pandi Peng ${ }^{4}$, Chu Gao ${ }^{5}$, \\ Xiaolong $\mathrm{Xu}^{1}$, Yachao Ma ${ }^{1}$, Mei Liu ${ }^{2}$, Liu Yang ${ }^{1,5 *}$ and Zhuojing Luo ${ }^{1,5 *}$
}

${ }^{1}$ Institute of Orthopedic Surgery, Xijing Hospital, Fourth Military Medical University, Xi'an, China, ${ }^{2}$ Pharmacy Department, Air Force Hospital of Eastern Theater Command, Nanjing, China, ${ }^{3}$ Rehabilitation Department, Dongchangfu Traditional Chinese Medicine Hospital, Liaocheng, China, ${ }^{4}$ Institute of Flexible Electronics, Northwestern Polytechnical University, Xi'an, China, ${ }^{5}$ Medical Research Institute, Northwestern Polytechnical University, Xi'an, China

Low back pain (LBP) is a global health issue. Intervertebral disc degeneration (IDD) is a major cause of LBP. Although the explicit mechanisms underpinning IDD are unclear, endoplasmic reticulum (ER) stress caused by aberrant unfolded or misfolded proteins may be involved. The accumulation of unfolded/misfolded proteins may result in reduced protein synthesis and promote aberrant protein degradation to recover ER function, a response termed the unfolded protein response. A growing body of literature has demonstrated the potential relationships between ER stress and the pathogenesis of IDD, indicating some promising therapeutic targets. In this review, we summarize the current knowledge regarding the impact of ER stress on the process of IDD, as well as some potential therapeutic strategies for alleviating disc degeneration by targeting different pathways to inhibit ER stress. This review will facilitate understanding the pathogenesis and progress of IDD and highlights potential therapeutic targets for treating this condition.

Keywords: low back pain, intervertebral disc degeneration, endoplasmic reticulum, unfolded protein response, cellular homeostasis

\section{INTRODUCTION}

According to a systematic analysis by the Global Burden of disease study 2019, approximately $80 \%$ of individuals experience low back pain (LBP) during their lifetime. For the increased population and aging, disability-adjusted life-years (DALYs) caused by LBP increased by $46.9 \%$ between 1990 and 2019. Because of the highest prevalence and years of life lived with disability (YLDs) of all musculoskeletal diseases, LBP has caused a substantial socioeconomic burden on society (Diseases and Injuries, 2020; Cieza et al., 2021). Intervertebral disc degeneration (IDD), which is characterized by abnormalities in local physiological structure [reduced hydration of the nucleus pulposus (NP), disorganization of the annulus fibrosus (AF), and calcification of the cartilage endplates (CEP)] and radiological evidence [decreased disc height in radiography and reduced T2 signal intensity in magnetic resonance imaging (MRI)], is a major cause of LBP (Luoma et al., 2000; Brinjikji et al., 2015; Von Forell et al., 2015; Zheng and Chen, 2015; Luoma et al., 2016; van den Berg et al., 2017; Taylor and Bishop, 2019). The commonly used clinical therapeutic methods focus on symptomatic relief from pain by conservative treatments (restricted exercise, low-tension traction, physical therapy, injections, etc.) or surgical measures (disc decompression, disc replacement or spinal fusion) (Raj, 2008; Urits et al., 2019). However, these interventions possess a number of limits. As final selections, surgical operations usually bring heavy cost, surgery risks and a long journey of 
rehabilitation to patients. While conservative treatment showed no effect on inhibiting the progression of IDD or restoring the dampened IVD structure (Raj, 2008; Urits et al., 2019; O'Keeffe et al., 2020; Meroni et al., 2021). Thus, seeking new therapeutic strategies for inhibiting IDD process is a burning question for clinical researchers.

Intervertebral discs (IVDs) consist of three basic anatomical parts: the inner NP, outer AF, and superior and inferior CEP, which connect the vertebrae and offer flexibility to the spine (Adams and Dolan, 2012; Gopal et al., 2012; Pattappa et al., 2012; Kepler et al., 2013; Vergroesen et al., 2015). The intact IVD elements help the spine resist mechanical stress and maintain the range of motion. While a dampened IVD structure disrupts the stability of spine and thus leads to the pathogenic progress of IDD (Urban et al., 2004; Inoue and Espinoza Orias, 2011). The pathogenesis of IDD is complex and includes various risk factors, such as genetic variation, disorganized immune system status, excessive loading, circadian rhythm disorders, and aging (Ma et al., 2015; Bian et al., 2017; Dudek et al., 2017; Kitis et al., 2018; Xu et al., 2019). At cellular and molecular levels, these risk factors induce abnormal mitochondrial and endoplasmic reticulum (ER) function, impair redox and immunity homeostasis, and ultimately trigger IVD cell senescence and apoptosis, resulting in IDD (Chen et al., 2016; Cheng et al., 2018; Luo et al., 2019a; Liao et al., 2019). Although numerous factors contribute to the process of IDD, our understanding of its molecular mechanisms remains limited.

A stable extracellular matrix (ECM) is critical for maintaining IVD homeostasis. In NP tissue, synthesized ECM, mainly proteoglycans and type-II collagens, is highly hydrated, which helps the IVDs resist the axial mechanical loading. While in AF tissue, type-I collagens constitute the main components of the ECM, which shows the ability to bear the lateral deformation (Vergroesen et al., 2015; Bian et al., 2017). At the subcellular level, the ER plays critical roles in the synthesis of ECM on account of its function for protein folding, lipid/ion transfer, signaling, and metabolism. However, various stimulus for IVDs, such as hypoxia, starvation, inflammation, abnormal mechanical loading, imbalances in reactive oxygen species (ROS), and perturbation of $\mathrm{Ca}^{2+}$ levels, may trigger ER stress by interrupting protein folding and/or modification and thus dampen the synthesis of ECM. The evidence mentioned above implies that ER stress may be involved in the process of IDD (Wu et al., 2018; Reibe and Febbraio, 2019; Carlton et al., 2020).

Here, we review the molecular basis for the sensing and response of ER stress, the involvement of ER stress in the pathogenesis of IDD, and some promising therapeutic strategies by targeting ER stress pathway.

\section{MOLECULAR BASIS FOR THE SENSING AND RESPONSE OF ER STRESS}

To respond to ER stress, cells activate an adaptive response mainly with three distinct arms to reduce the quantity of mismodified proteins, which is called unfolded protein response (UPR) (Hetz, 2012; Senft and Ronai, 2015; Shpilka and Haynes, 2018; Hofmann et al., 2019). As an important responsive mechanism in cells under ER stress, UPR has been implicated in many chronic diseases such as cardiovascular diseases, musculoskeletal disorders, neurodegeneration, and endocrine disease (Ghosh et al., 2019; Hetz et al., 2019; Naiel et al., 2019; Pedersen and Maksymowych, 2019; Yang Y. et al., 2020; Hazari et al., 2020; Ji et al., 2020). Usually, the UPR senses the protein-folding status within the ER lumen and transduces this information to the cytosol and nucleus to relieve overloading of unfolded proteins, which is called adaptive UPR. However, under sustained ER stress conditions, the UPR triggers proapoptotic programs to eliminate existing cells and thus may aggravate the disease course, which is termed as proapoptotic UPR (Senft and Ronai, 2015; Shpilka and Haynes, 2018). The UPR signaling pathway involves two main components: ER stress sensors at the ER membrane and downstream transcription factors in the cytosol and nucleus. The whole picture of ER stress sensors and the downstream transcription factors were detailedly described in Figure 1.

In the absence of ER stress, the ER chaperone binding immunoglobulin protein [BiP, also known as $78-\mathrm{kDa}$ glucoseregulated protein (GRP78) or heat shock protein A5 (HSPA5)], binds to the luminal domain of three ER transmembrane protein sensors, namely inositol-requiring kinase 1a (IRE1 $\alpha$ ), protein kinase RNA-like ER kinase (PERK), and activating transcription factor 6 (ATF6), and inhibits their activation. Upon ER stress, BiP binds to excessively accumulated misfolded or unfolded proteins in the ER and loses the ability to inhibit the three ER sensors, ultimately resulting in the occurrence of the UPR (Gardner et al., 2013; Senft and Ronai, 2015; Shpilka and Haynes, 2018; Koopman et al., 2019; Kopp et al., 2019; Preissler and Ron, 2019; Siwecka et al., 2019). Based on the different sensors, the UPR is classically divided into three branches: IRE1 $\alpha$, PERK, and ATF6 (Senft and Ronai, 2015; Hetz and Saxena, 2017; Hofmann et al., 2019; Koopman et al., 2019; Mogilenko et al., 2019).

IRE1a, which is evolutionarily conserved in eukaryon, contains RNase and kinase functions under ER stress. Upon activation, IRE1 $a$ dimerizes and autotransphosphorylates, acting as a UPR transducer that leads to excision of a 26-nucleotide intron from the mRNA encoding the transcription factor X boxbinding protein 1 (XBP1) within the cytosol. After excision, the reading frame of $X B P 1 \mathrm{mRNA}$ transforms into an active and stable form, which is termed spliced XBP1 (XBP1s). XBP1s translocates to the nucleus to upregulate its target genes, which support cell survival, restore proteostasis, and activate ER-associated degradation (ERAD) (Calfon et al., 2002; Walter and Ron, 2011; Senft and Ronai, 2015; Chalmers et al., 2017; Hetz and Saxena, 2017). During the ERAD, the misfolded/unfolded proteins are transferred out of ER lumen and then degraded via proteasome-dependent pathway. In addition, IRE1a targets a group of endogenous mRNAs for degradation of ER-located proteins and certain microRNAs due to its RNase activity, a process termed regulated IRE1 $\alpha$-dependent decay (RIDD). In RIDD process, decreased mRNA abundance may result in a decreased level of protein folding and thus recover the ER 


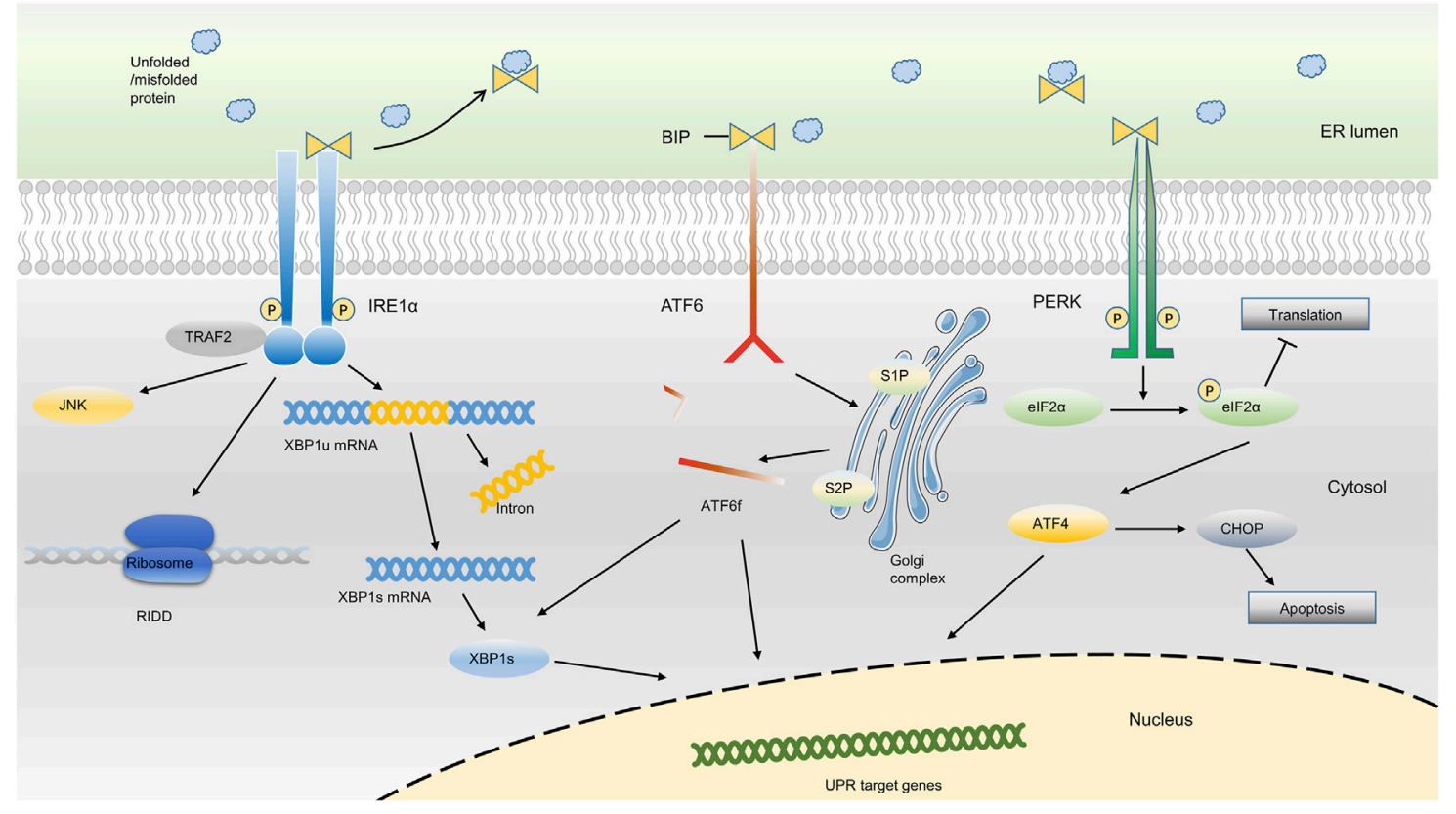

FIGURE 1 | ER stress-sensing and three arms of UPR. Upon ER stress, BiP binds to unfolded proteins in the ER lumen and activates three ER sensors, ultimately resulting in the occurrence of the UPR. The three arms of UPR (PERK, IRE1 $\alpha$ and ATF6) activate a series of downstream transcription factors in the cytosol and nucleus, which thus reduce the protein synthesis or promote protein degradation, or ultimately result in cell apoptosis.

homeostasis (Maurel et al., 2014; Carew et al., 2018; Huang et al., 2019).

In addition, ER stress also triggers the activation of PERK through the dimerization, oligomerization and autophosphorylation of PERK, which inhibits protein synthesis via direct phosphorylation of eukaryotic translation initiator factor $2 \alpha$ (eIF2 $\alpha$ ) (Back et al., 2009; Feng et al., 2014; AbdelNour et al., 2019; Balsa et al., 2019). Phosphorylation of eIF2 $a$ by PERK subsequently leads to the transcription of the mRNA encoding activating transcription factor 4 (ATF4), which promotes ER adaptation and cell survival (B'Chir et al., 2013; Balsa et al., 2019). PERK signaling also regulates the expression of several microRNAs that attenuate protein translational load or expand ER capacity. For example, miR-30c-2-3p is induced by the PERK pathway of the UPR and governs the expression of XBP1, which promotes secretory capacity and cell survival in the adaptive UPR (Byrd et al., 2012). In addition, PERKdependent miR-211 induction directly targets the Chop promoter to repress $\mathrm{C} / \mathrm{EBP}$ homologous protein (CHOP) expression and thereby protects cells from apoptotic commitment (Chitnis et al., 2012).

Moreover, ER stress also leads to the activation of ATF6, a member of the transcription factor family containing a basic Leu zipper (bZIP) structure. The ATF6 has two main isoforms, ATF6 $\alpha$ and ATF6 $\beta$ (Glembotski et al., 2019). When cells undergo ER stress, ATF6 is readily trafficked from the ER to the Golgi apparatus. After being processed by site 1 protease $(\mathrm{S} 1 \mathrm{P})$ and site 2 protease (S2P), ATF6 is transformed into a cytosolic fragment termed ATF6f and transcriptionally upregulates genes encoding components involved in ERAD and XBP1 within the nucleus (Fass, 2019; Glembotski et al., 2019; Oka et al., 2019; Waldherr et al., 2019). Although the activation of ATF6 and XBP1 belong to different arms of UPR, they can both promote the transcription of genes encoding ER chaperones, and enzymes that help the protein secretion or the degradation of misfolded protein, indicating a potential synergistic effect of different arms of UPR (Shoulders et al., 2013).

Although all three arms of the UPR are crucial for cells to respond to ER stress, these sensors may be differentially activated in different conditions. For example, IRE1 $\alpha$ and PERK are rapidly activated when the ER calcium content is depleted in CHO cells (DuRose et al., 2006), whereas reduced glycosylation or altered redox metabolism in HeLa-TetOff cell line preferentially activate ATF6 arm of UPR (Maiuolo et al., 2011). Consequently, it is necessary to distinguish different inducers of ER stress in different disease models.

\section{ER STRESS AND THE UPR IN IDD}

Previous studies have reported that ER stress is a major underlying mechanism involved in various musculoskeletal system disorders, such as rheumatoid arthritis (RA) (Yoo et al., 2012; Savic et al., 2014; Rahmati et al., 2018), osteoarthritis (OA) (Hosseinzadeh et al., 2016; Tang et al., 2017), myodegenerative disorders (Kustermann et al., 2018), abnormal bone mass (Collison, 2018; Li et al., 2018), and certain developmental diseases (dwarfishness, spondylolisthesis, 
etc.) (Woodman, 2013; Mullan et al., 2017; Zheng et al., 2019). Due to abundant synthesis and the secretion of matrix proteins, the ER in IVD cells is highly vulnerable to external stimuli. Moreover, the microenvironment of IVDs is quite complicated, suffering from high osmotic pressure, low $\mathrm{pH}$, oxidative stress and mechanical load (Vergroesen et al., 2015). The increased expression of ER stress-related proteins and ER stress-related apoptosis markers, such as GRP78, CHOP, and caspase 12, have been reported in NP tissues of IDD patients (Zhao et al., 2010; Liao et al., 2019). The comparison of human NP samples with different degrees of degeneration revealed that increased expression levels of GRP78 and CHOP were positively correlated with the Pfirrmann grades of IDD (Liao et al., 2019). These research results strongly indicate that ER stress participates in the process of IDD.

Oxidative stress and inflammatory reaction are two major factors involved in IDD pathogenesis. Accumulation of ROS and proinflammatory factors can induce the degradation of ECM and reduce the number of IVD cells, which leads to the occurrence and development of IDD (Chen et al., 2016; Cheng et al., 2018). $\mathrm{H}_{2} \mathrm{O}_{2}$, a classic oxidative stress inducer, upregulates GRP78, CHOP, and caspase 12 in vitro and switches NP cells towards apoptosis, indicating oxidative stress is an ER stress inducer in IDD process (Luo et al., 2019a). Although it is still unclear how ROS signaling induces ER stress in IVDs, some possible mechanisms should be taken into consideration. On one hand, ROS disturbs the correct disulfide bond formation and proper protein folding, which may initiate the ER stress (Wang et al., 2016; Ochoa et al., 2018). On the other hand, ER-mitochondrial $\mathrm{Ca}^{2+}$ crosstalk may also play an important role in ROS-induced ER stress (Ochoa et al., 2018; Lin et al., 2021). Moreover, both IL1 and TNF- $\alpha$, two well-established proinflammatory cytokines involved in the development of IDD, can also induce ER stress and bias towards apoptotic signaling of IVD cells. Xiaotao Wang et al. verified that $10 \mathrm{ng} / \mathrm{ml} \mathrm{TNF-} \alpha$ for $24 \mathrm{~h}$ triggered the increased expression of $\mathrm{BiP}$ and the apoptosis of rat NP cells (Chen et al., 2018; Chen et al., 2019b). Xiangyang Wang et al. reported that $24 \mathrm{~h}$ treatment with $75 \mathrm{ng} / \mathrm{ml} \mathrm{IL-1} \beta$ caused an increase in two UPR markers, CHOP and ATF6, in passage 2 human NP cells (Xu et al., 2017). Contrary to these findings, Olga et al. reported that TNF- $\alpha$ ( 5 and $10 \mathrm{ng} / \mathrm{ml}$ ) did not activate ER stress, whereas IL- $1 \beta$ (5 and $10 \mathrm{ng} / \mathrm{ml}$ ) activated gene and protein expression of GRP78 but did not influence $\left[\mathrm{Ca}^{2+}\right]_{\mathrm{i}}$ flux and expression of CHOP in human primary NP cells (Krupkova et al., 2018). These discrepancies may be due to the distinct resources of NP cells or different dosages of IL-1 $\beta$ used.

Although ER stress have been verified an important mediator between inflammation/ROS and IDD, the ER stress can also induce inflammatory condition or ROS accumulation, which may in turn exacerbate the process of IDD induced by these factors. For examples, ER stress can initiate the ligand-independent activation of TRAIL receptors, which then results in caspase-8/ FADD/RIPK1-depezndent nuclear factor-kappa B (NF- $\mathrm{B}$ ) activation and inflammatory cytokine production (Sullivan et al., 2020). NOD1 and NOD2, two members of the NODlike receptor family, can also mediate ER stress-induced inflammation (Keestra-Gounder et al., 2016). Lu Chen et al. reported that the activation of XBP1 pathway favored the phosphorylation and nuclear translocation of p65 subunit of NF- $\kappa B$ in NP cells, indicating a potential crosstalk between ER stress and inflammation in the process of IDD (Chen et al., 2019c). In addition, ER stress can also promote ROS production. CHOP was reported to transcriptionally activate Erola and thus increase ROS level during ER stress. Moreover, Erola causes inositol-1,4,5-trisphosphate receptor (IP3R)-mediated $\mathrm{Ca}^{2+}$ leakage from the ER (Anelli et al., 2012). An excess of $\mathrm{Ca}^{2+}$ released from the ER can be taken up by mitochondria, which may result in an excessive release of cytochrome $\mathrm{C}$ from the mitochondrial matrix and thus enhance the production of ROS (Boehning et al., 2003; Wozniak et al., 2006). ER stress induced by impaired calcium homeostasis was also observed in NP cells, indicating a potential crosstalk between oxidative stress and ER stress in the process of IDD (Luo et al., 2019b).

Excessive mechanical loading is positively correlated with the process of IDD (Adams et al., 2000; Von Forell et al., 2015; Desmoulin et al., 2019). It has been reported that 1.0 MPa static compression was sufficiently high to induce an increase in CHOP, caspase 12, and cleaved caspase12, resulting in apoptosis in rat NP cells (Wang et al., 2018). Li et al. reported that $20 \%$ surface elongation at a frequency of 6 cycles/min was also an external factor triggering ER stress and promoting NP cells apoptosis ( $\mathrm{Li}$ et al., 2017). Moreover, supraphysiological tension also increased the expression of $\mathrm{CHOP}$ and triggered apoptosis in $\mathrm{AF}$ cells (Zhang et al., 2011). These studies indicated that mechanical stress was an ER stress inducer for IVD cells and excessive loading-induced ER stress resulted in the process of IDD. At molecule level, mechanical signaling transduction may mediate the excessive loading-induced ER stress. Piezo type mechanosensitive ion channel component 1 (Piezo1) protein, an important mechanosensitive ion channel, has been reported to participate in the mechanical signal transduction of eukaryotic cells (Zhao et al., 2018). Cao Yang et al. reported that increased ECM stiffness promoted the expression of mechanosensitive ion channel PIEZO1 and ER stress markers (GRP78 and CHOP). Piezo1 knockdown attenuated stiff ECM-induced ER stress and thus inhibited NP cell senescence and apoptosis (Wang et al., 2021). Furthermore, some other mechanosensitive molecules, such as transient receptor potential vallinoid-4 (TRPV4), $\mathrm{N}$-cadherin adhesions, connexin 43 connexons or integrins, were reported to participate in the mechanical signal transduction of IVD cells and disfunction of which was connected with the process of IDD. Whether the mechanosensitive molecules mentioned above involves in mechanical loading-induced ER stress remains to be seen in further experiments.

Metabolic disturbance is another common incentive for the process of IDD. Due to hypoxia, anaerobic glycolysis is the main energy source of NP tissue, which results in an increased lactate production and a decreased $\mathrm{pH}$ level. High lactic acid concentration reduces the synthesis rates of matrix protein and promotes the apoptosis of NP cells, which leads to the process of IDD (Wu et al., 2014). Acidic environment was reported to result in an increase in GRP78, CHOP, caspase12, while the blockade of acid-sensing ion channel 1a (ASIC1a) 
partially alleviated IDD by the inhabitation of ER stress (Xie et al., 2017; Xie et al., 2018). These results indicate acid-sensing ion channel is enrolled in low $\mathrm{pH}$-induced ER stress in IVDs. Moreover, abnormal glucose level is also involved in the occurrence of IDD (Zhang et al., 2019a). In hyperglycemic condition, advanced glycation end products (AGEs) accumulate in peripheral tissue and thus reduce collagen affinity for some key molecules (Gautieri et al., 2014). Addition of AGEs has been proved to increase the expression of ER stress as well as UPR markers and thus induce the apoptosis of NP cells. In addition, glucose deprivation time-dependently upregulated the levels of p-eIF2 $\alpha$ and ATF4 in NP cells, suggesting that ER stress is triggered by nutrient deprivation via the eIF2a/ATF4 pathway (Chang et al., 2017).

\section{POTENTIAL THERAPEUTIC STRATEGIES FOR IDD BY TARGETING ER STRESS AND UPR}

Accumulated evidence suggests that IVDs are easily subject to ER stress, which may play a pivotal role in the process of IDD. Given the role of ER stress and UPR in IVD function and dysfunction, targeting molecules in inhibiting ER stress and modulating UPR is undoubtedly an attractive therapeutic method for disc degeneration.

Given the effect of stabilizing the folded protein and promoting the protein transfer out of the ER, chemical chaperones for reducing the level of unfolded protein in the ER lumen are effective drugs for inhibiting ER stress (Welch and Brown, 1996; Xie et al., 2002). Zengwu Shao et al. reported that tauroursodeoxycholic acid (TUDCA), a FDA-approved bile acid with chaperone properties, was able to alleviate the 1.0 MPa compression-induced apoptosis and necroptosis of NP cells by inhibiting ER stress (Wang et al., 2018). Another FDA-approved chemical chaperone, 4-phenylbutyricacid (4-PBA), has also been verified to alleviate IDD by inhibiting ER stress in different experiment condition, such as the application of cyclic tension on AF cells and the treatment of AGEs, $\mathrm{H}_{2} \mathrm{O}_{2}$, or TNFa on NP cells (Chen et al., 2018; Chen J. et al., 2019; Luo et al., 2019a; Luo et al., 2019b). These results indicated that inhibiting ER stress by these chemical chaperones is a promising strategy for ameliorate the process of IDD.

Targeting molecules in the three arms of UPR to inhibit IVD cell death induced by excessive ER stress might be promising for future IDD therapy. Takeshi Fujii et al. reported that the PERKATF4 pathway was activated in human degenerative IVD tissues (Fujii et al., 2018). Pharmacological inhibition of PERK (GSK2606414) significantly suppressed the starvation-induced expression of TNF, ADAMTS5 transcripts and apoptosis in human AF cells. This result indicated that PERK inhibitors might be promising drugs for IDD (Fujii et al., 2018). However, Lu Chen et al. reported that both PERK inhibitor and IRE1 inhibitor increased cell apoptosis induced by TNF- $\alpha$ and reduced cell proliferation of NP cells, which seemed contradicted to the previous result (Chen et al., 2018). On the one hand, the discrepancy between the two results could attribute to the different cell types as well as in vitro models. On the other hand, PERK inhibitor used in the two studies was reported to inhibit cellular RIPK1 at a lower concentration, indicating some nonspecific effects of these inhibitors (Rojas-Rivera et al., 2017). In addition, previous studies showed that silencing some molecules in the downstream of UPR, such as ATF4 and CHOP, successfully reduced the expression of IL-6 and prevented the process of IDD, indicating that manipulating some molecules in UPR pathway could be a potential molecular target for IDD prevention (Fujii et al., 2018; Krupkova et al., 2018). Recently, Dike Ruan et al. reported that knockdown of IRE1- $\alpha$ or PERK was able to recover the dampened ECM synthesis induced by TNF- and IL-1, while knockdown of ATF6 showed no protective effect in this inflammation-induced model (Wen et al., 2021). However, ATF6 small interfering RNA (siRNA) markedly inhibited the tert-butyl hydroperoxide-induced apoptosis of CEP cells, indicating its protective effect in an oxidative stress-induced model (Xie et al., 2020). These results implied that not all three arms of UPR were simultaneously involved in the IDD induced by single pathogenic factor. It is very important to determine which sub-pathway is involved in a certain pathogenic process and provide personalized treatment.

Targeting autophagy-associated molecules might be another effective method for alleviating the process of IDD induced by overwhelming ER stress. Once the UPR pathway cannot alleviate the ER stress, autophagy and even apoptosis are eventually activated (Hetz, 2012). The PERK-eIF2a-ATF4 pathway has been confirmed to help the formation of the autophagosome. ATF4 and CHOP transcriptionally regulate numerous autophagy-associated genes (ATGs) by binding these factors to specific promoter cis elements of ATGs (B'Chir et al., 2013). In addition, the IRE1 arm also plays an important role in the activation of autophagy. Activation of IRE1a recruits the adaptor protein TNF receptor-associated factor 2 (TRAF2), which activates the apoptosis signal-regulating kinase 1 (ASK1) pathway and its downstream target JUN N-terminal kinase (JNK), enabling the dissociation of Beclin-1 (an essential autophagy regulator), activation of PI3K signaling, and triggering autophagy (Deegan et al., 2013; Liu et al., 2020). Meiqing Wang et al. showed that activating autophagy by rapamycin, an inhibitor of MTORC1, markedly reduced p-EIF2AK3-mediated ER stress-apoptosis in flow fluid shear stress-treated chondrocytes. This result implied that autophagy activation might be a promising strategy for inhibiting ER stress in IDD process (Yang H. et al., 2020). It has been reported that 1.0 $\mathrm{MPa}$ static compression is sufficiently high to trigger ER stress and promote the conversion of LC3B-I to LC3B-II (hallmark at an early stage of autophagy) (Ma et al., 2013; Wang et al., 2018). Transmission electron microscope (TEM) images also revealed that both the expansive endoplasmic reticula and autophagosomes were present in NP cells following exposure to $1.0 \mathrm{MPa}$ for $36 \mathrm{~h}$ (Ma et al., 2013). In addition, knockdown of ATF4 with siRNA significantly attenuated the conversion of LC3I to LC3-II, which also confirmed the link between the UPR and autophagy in IDD (Chang et al., 2017). Up to now, many smallmolecule modulators of mammalian autophagy have been verified to alleviated IDD, indicating a huge potential for 
TABLE 1 | Promising therapeutic treatment targeting ER stress.

\begin{tabular}{|c|c|c|c|}
\hline Categories & Name & Mechanism of action & Ref \\
\hline Chemical chaperones & $\begin{array}{l}\text { TUDCA } \\
4-P B A\end{array}$ & Reducing unfolded protein in ER & $\begin{array}{l}\text { Wang et al. (2018) } \\
\text { (Chen et al., 2018; Chen et al., 2019a; Luo et al., 2019a; Luo et al., 2019b) }\end{array}$ \\
\hline UPR regulators & $\begin{array}{l}\text { GSK2606414 } \\
\text { siRNA for PERK } \\
\text { siRNA for ATF4 } \\
\text { siRNA for CHOP } \\
\text { siRNA for IRE1- } \alpha \\
\text { siRNA for ATF6 }\end{array}$ & $\begin{array}{l}\text { PERK inhibitor } \\
\text { Inhibiting PERK-elF2 } \alpha-A T F 4-C H O P \text { pathway } \\
\text { Inhibiting IRE1- } \alpha \text { arm } \\
\text { Inhibiting ATF6 arm }\end{array}$ & $\begin{array}{l}\text { Fujii et al. (2018) } \\
\text { Wen et al. (2021) } \\
\text { Fujii et al. (2018) } \\
\text { (Fujii et al., 2018; Krupkova et al., 2018) } \\
\text { Wen et al. (2021) } \\
\text { Xie et al. (2020) }\end{array}$ \\
\hline Autophagy regulator & $\begin{array}{l}\text { Exosomes } \\
\text { Rapamycin }\end{array}$ & $\begin{array}{l}\text { Activating autophagy and inhibiting ER stress } \\
\text { Inducing p-EIF2AK3-mediated ER stress }\end{array}$ & $\begin{array}{l}\text { (Liao et al., 2019; Shi et al., 2021) } \\
\text { Yang et al. (2020a) }\end{array}$ \\
\hline
\end{tabular}
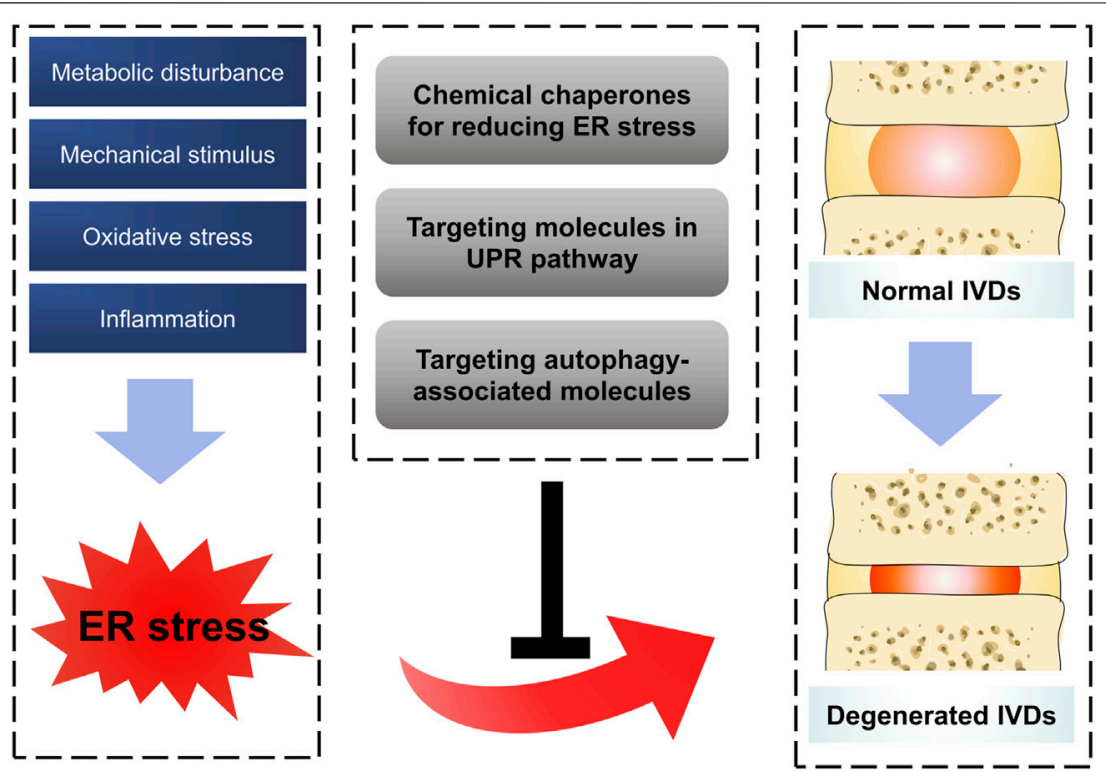

FIGURE 2| Schematic diagram for targeting ER stress to prevent IDD. Oxidative stress, inflammation, mechanical stimulus and metabolic disturbance are common factors affecting IVDs, which were confirmed to trigger ER stress in IDD process by a series of reasonable evidence. Some therapeutic strategies by targeting ER stress showed promising effect on ameliorating the process of IDD.

medical application (Chen et al., 2016; Zhang et al., 2019b; Wang et al., 2020). Exosomes derived from bone marrow mesenchymal stem cells also showed potential therapeutic effect for IDD model by activating autophagy and inhibiting ER stress (Liao et al., 2019; Shi et al., 2021), Some promising therapeutic treatment targeting ER stress pathway has been listed in Table 1.

\section{DISCUSSION AND PROSPECTS}

IDD is a major cause of LBP that presents an important scientific and social issue and has received substantial attention. DALYs and YLDs caused by this disc degenerative disease have imposed huge burden for the individuals and the whole society (Diseases and Injuries, 2020; Cieza et al., 2021). Due to the lack of efficient interventions to prevent the occurrence or halt the progression of IDD, it is necessary for us to figure out molecule mechanism of IDD and find out some effective therapeutic treatment.
The risk factors of IDD are complicated and its pathogenesis is still unclear. As large polymerized molecules in the ECM, collagens undergo extensive post-translational modifications and folding in the ER, which pose susceptibility to ER stress. Over the past 10 years, studies have indicated that ER stress results in aberrant IVD cell functions, such as decreased cell proliferation and ECM synthesis, increased cell apoptosis, senescence, ECM degradation, and secretion of various inflammatory cytokines. In order to handle the impact of ER stress, the activation of the UPR and other defensive processes orchestrates diverse pathways to recover IVD cell functions (Senft and Ronai, 2015; Krupkova et al., 2018; Chen et al., 2019b; Liao et al., 2019; Luo et al., 2019a; Luo et al., 2019b). This review summarized the relationship between ER stress and IDD and highlighted potential therapeutic targets for treating this condition (Figure 2). Although there is still a long way to realize the clinical transformation for these therapeutic strategies, drugs targeting ER stress pathway showed their charming potential. On the one hand, more studies in recent years attempted to illustrate the exact mechanism between ER stress and 
the pathogenesis of IDD, and more effective therapeutic strategies have been verified in pre-clinical experiments (Chen et al., 2019c; Liao et al., 2019). On the other hand, some drugs targeting ER stress have been accepted in clinical trials in patients and show some promising outcomes. For example, Bip administration showed the effectiveness and safety in patients with active RA. Compared with placebo group, patients in 5 or $15 \mathrm{mg}$ Bip group showed significantly lower serum concentrations of C-reactive protein after 2-week treatment (Kirkham et al., 2016). Numerous interventional measures targeting ER stress pathway have been adopted in some preclinical experiments and even clinical trials, however, there still some tough challenges for the process of clinical transformation. First of all, among the limitations of these clinical trials were their small sample size as they were designed as randomized and controlled experiment, indicating a dampening credibility for their results. Furthermore, some local delivery systems with noninvasive or less invasive characteristics remain to be explored for the purpose of improving drugs' efficiency and reducing their side effects. Last but not least, there are still some questions to be solved in ER stress response mechanism. Whether can the aberrant ECM components (collagens or proteoglycans) directly trigger the ER stress in IDD process? Do all three arms of UPR play a role in ER stress-induced IDD in a coordinated manner? What is the overall perspective of the crosstalk between IDD inducers and response mechanism of ER stress in the development of IDD? For screening out special therapeutic drugs, it is quite helpful to address these problems.

Data suggest that ER stress is a pivotal mediator in the pathogenesis of IDD in many recent experiments, whereas the direct evidence is still limited. For example, most studies paid their attention on the activation of ER stress or UPR pathway in IVDs via the expression of some ER stress or UPR markers, such as GRP78, CHOP or caspase 12, few studies showed the accumulation of misfolded protein in IVD cells in the process of IDD. To date, most ER stress-mediated IDD experiments in vitro have been performed on NP cells. Limited attention has been paid to ER stress-mediated degeneration of the AF, CEP, and even the entire structure of the functional spinal unit. Moreover, the exact relationships among different mechanisms responsible for IDD require further elucidation. For example, in spite of UPR, many ER stress-related models in vitro also showed some subcellular changes related to autophagy and mitochondrial problems (Hetz, 2012; Senft and Ronai, 2015). Cao Yang et al. also reported that berberine, an isoquinoline alkaloid usually functioning by modulating autophagy or

\section{REFERENCES}

Abdel-Nour, M., Carneiro, L. A. M., Downey, J., Tsalikis, J., Outlioua, A., Prescott, D., et al. (2019). The Heme-Regulated Inhibitor Is a Cytosolic Sensor of Protein Misfolding that Controls Innate Immune Signaling. Science 365 (6448), eaaw4144. doi:10.1126/science.aaw4144

Adams, M. A., and Dolan, P. (2012). Intervertebral Disc Degeneration: Evidence for Two Distinct Phenotypes. J. Anat. 221 (6), 497-506. doi:10.1111/j.14697580.2012.01551.x

Adams, M. A., Freeman, B. J. C., Morrison, H. P., Nelson, I. W., and Dolan, P. (2000). Mechanical Initiation of Intervertebral Disc Degeneration. Spine 25 (13), 1625-1636. doi:10.1097/00007632-200007010-00005 mitochondrial dynamics, successfully inhibited the process of IDD by inhibiting ER stress. These results hinted that the crosstalk among different mechanisms of cell response might impose a comprehensive effect on maintaining physiological homeostasis for IVD cells. Thus, some small molecule drugs with a broad spectrum of activity these cellular responses, such as melatonin, quercetin, resveratrol or curcumin, may have a wide range of potential applications on IDD prevention. Based on our comprehensive understanding of ER stress and its responsible mechanism in IDD, some translational approaches (the clinical use of targeted therapy, exosomes from stem cells, potential conventional drugs, etc.) are promising.

\section{CONCLUSION}

The research on the relationship between ER stress and the pathogenesis of IDD is still in its infancy, with a growing number of studies available supporting this view. Our work summarized the current knowledge regarding the impact of ER stress on the process of IDD, as well as some potential therapeutic methods for alleviating IDD by targeting ER stress pathway. Further studies to explore ER stress and its responsible mechanisms in IDD may offer more efficient therapeutic strategies to prevent or halt the process of disc degenerative diseases.

\section{AUTHOR CONTRIBUTIONS}

DW and HX contributed equally to this work. LY, ZL and DW conceived and designed the review. DW and $\mathrm{XH}$ prepared figures and table, and were the major contributors in writing the manuscript. CZ, CW, PP, CG, XX, ML and YM re-checked the manuscript. $\mathrm{LY}$ and $\mathrm{ZL}$ reviewed and revised the manuscript. All authors read and approved the final manuscript.

\section{FUNDING}

This work was supported by the National Natural Science Foundation of China (82020108019, 81730065 and 82002347) and Key Research and Development Program of Shaanxi (2021SF-022).

Anelli, T., Bergamelli, L., Margittai, E., Rimessi, A., Fagioli, C., Malgaroli, A., et al. (2012). Erolalpha Regulates $\mathrm{Ca}(2+)$ Fluxes At The Endoplasmic Reticulum-Mitochondria Interface (MAM). Antioxid Redox Signal 16 (10), 1077-1087. doi:10.1089/ ars.2011.4004

Antoniou, J., Steffen, T., Nelson, F., Winterbottom, N., Hollander, A. P., Poole, R. A., et al. (1996). The Human Lumbar Intervertebral Disc: Evidence for Changes in the Biosynthesis and Denaturation of the Extracellular Matrix with Growth, Maturation, Ageing, and Degeneration. J. Clin. Invest. 98 (4), 996-1003. doi:10.1172/JCI118884

Back, S. H., Scheuner, D., Han, J., Song, B., Ribick, M., Wang, J., et al. (2009). Translation Attenuation through eIF2a Phosphorylation Prevents Oxidative Stress and Maintains the Differentiated State in $\beta$ Cells. Cel Metab. 10 (1), 13-26. doi:10.1016/j.cmet.2009.06.002 
Balsa, E., Soustek, M. S., Thomas, A., Cogliati, S., García-Poyatos, C., MartínGarcía, E., et al. (2019). ER and Nutrient Stress Promote Assembly of Respiratory Chain Supercomplexes through the PERK-eIF2a Axis. Mol. Cel 74 (5), 877-890. e876. doi:10.1016/j.molcel.2019.03.031

B'chir, W., Maurin, A.-C., Carraro, V., Averous, J., Jousse, C., Muranishi, Y., et al. (2013). The eIF2a/ATF4 Pathway Is Essential for Stress-Induced Autophagy Gene Expression. Nucleic Acids Res. 41 (16), 7683-7699. doi:10.1093/nar/ gkt563

Bian, Q., Ma, L., Jain, A., Crane, J. L., Kebaish, K., Wan, M., et al. (2017). Mechanosignaling Activation of TGF $\beta$ Maintains Intervertebral Disc Homeostasis. Bone Res. 5, 17008. doi:10.1038/boneres.2017.8

Boehning, D., Patterson, R. L., Sedaghat, L., Glebova, N. O., Kurosaki, T., and Snyder, S. H. (2003). Cytochrome c Binds To Inositol $(1,4,5)$ Trisphosphate Receptors, Amplifying Calcium-Dependent Apoptosis. Nat. Cell. Biol. 5 (12), 1051-1061. doi:10.1038/ncb1063

Brinjikji, W., Diehn, F. E., Jarvik, J. G., Carr, C. M., Kallmes, D. F., Murad, M. H., et al. (2015). MRI Findings of Disc Degeneration Are More Prevalent in Adults with Low Back Pain Than in Asymptomatic Controls: A Systematic Review and Meta-Analysis. AJNR Am. J. Neuroradiol 36 (12), 2394-2399. doi:10.3174/ ajnr.A4498

Byrd, A. E., Aragon, I. V., and Brewer, J. W. (2012). MicroRNA-30c-2* Limits Expression of Proadaptive Factor XBP1 in the Unfolded Protein Response. J. Cel Biol 196 (6), 689-698. doi:10.1083/jcb.201201077

Calfon, M., Zeng, H., Urano, F., Till, J. H., Hubbard, S. R., Harding, H. P., et al. (2002). IRE1 Couples Endoplasmic Reticulum Load to Secretory Capacity by Processing the XBP-1 mRNA. Nature 415 (6867), 92-96. doi:10.1038/415092a

Cao, Y., Trillo-Tinoco, J., Sierra, R. A., Anadon, C., Dai, W., Mohamed, E., et al. (2019). ER Stress-Induced Mediator C/EBP Homologous Protein Thwarts Effector $\mathrm{T}$ Cell Activity in Tumors through T-Bet Repression. Nat. Commun. 10 (1), 1280. doi:10.1038/s41467-019-09263-1

Carew, N., Nelson, A., Liang, Z., Smith, S., and Milcarek, C. (2018). Linking Endoplasmic Reticular Stress and Alternative Splicing. Int. J. Mol. Sci. 19 (12), 3919. doi:10.3390/ijms19123919

Carlton, J. G., Jones, H., and Eggert, U. S. (2020). Membrane and Organelle Dynamics during Cell Division. Nat. Rev. Mol. Cel Biol 21, 151-166. doi:10.1038/s41580-019-0208-1

Chalmers, F., van Lith, M., Sweeney, B., Cain, K., and Bulleid, N. J. (2017). Inhibition of IRE1 $\alpha$-Mediated XBP1 mRNA Cleavage by XBP1 Reveals a Novel Regulatory Process during the Unfolded Protein Response. Wellcome Open Res. 2, 36. doi:10.12688/wellcomeopenres.11764.2

Chang, H., Cai, F., Zhang, Y., Xue, M., Liu, L., Yang, A., et al. (2017). Early-stage Autophagy Protects Nucleus Pulposus Cells from Glucose DeprivationInduced Degeneration via the $\mathrm{P}$-eIF2a/ATF4 Pathway. Biomed. Pharmacother. 89, 529-535. doi:10.1016/j.biopha.2017.02.074

Chen, D., Xia, D., Pan, Z., Xu, D., Zhou, Y., Wu, Y., et al. (2016). Metformin Protects against Apoptosis and Senescence in Nucleus Pulposus Cells and Ameliorates Disc Degeneration In Vivo. Cell Death Dis 7 (10)-e2441. doi:10.1038/cddis.2016.334

Chen, J., Lin, Z., Deng, K., Shao, B., and Yang, D. (2019a). Tension Induces Intervertebral Disc Degeneration via Endoplasmic Reticulum Stress-Mediated Autophagy. Biosci. Rep. 39 (8), BSR20190578. doi:10.1042/BSR20190578

Chen, L., Liu, L., Xie, Z.-Y., Wang, F., Sinkemani, A., Zhang, C., et al. (2018). Endoplasmic Reticulum Stress Facilitates the Survival and Proliferation of Nucleus Pulposus Cells in TNF- $\alpha$ Stimulus by Activating Unfolded Protein Response. DNA Cel Biol. 37 (4), 347-358. doi:10.1089/dna.2017.4029

Chen, L., Liu, L., Xie, Z. Y., Wang, F., Zhu, L., Zhang, C., et al. (2019b). Protein Kinase RNA-like ER Kinase/eukaryotic Translation Initiation Factor $2 \alpha$ Pathway Attenuates Tumor Necrosis Factor Alpha-Induced Apoptosis in Nucleus Pulposus Cells by Activating Autophagy. J. Cel Physiol 234 (7), 11631-11645. doi:10.1002/jcp.27820

Chen, L., Xie, Z. Y., Liu, L., Zhu, L., Wang, F., Fan, P., et al. (2019c). Nuclear FactorKappa B-dependent X-Box Binding Protein 1 Signalling Promotes the Proliferation of Nucleus Pulposus Cells under Tumour Necrosis Factor Alpha Stimulation. Cell Prolif 52 (2), e12542. doi:10.1111/cpr.12542

Cheng, X., Zhang, L., Zhang, K., Zhang, G., Hu, Y., Sun, X., et al. (2018). Circular RNA VMA21 Protects against Intervertebral Disc Degeneration through Targeting miR-200c and X Linked Inhibitor-Of-Apoptosis Protein. Ann. Rheum. Dis. 77 (5), 770-779. doi:10.1136/annrheumdis-2017-212056
Chitnis, N. S., Pytel, D., Bobrovnikova-Marjon, E., Pant, D., Zheng, H., Maas, N. L., et al. (2012). miR-211 Is a Prosurvival microRNA that Regulates Chop Expression in a PERK-dependent Manner. Mol. Cel 48 (3), 353-364. doi:10.1016/j.molcel.2012.08.025

Cieza, A., Causey, K., Kamenov, K., Hanson, S. W., Chatterji, S., and Vos, T. (2021). Global Estimates of the Need for Rehabilitation Based on the Global Burden of Disease Study 2019: a Systematic Analysis for the Global Burden of Disease Study 2019. Lancet 396 (10267), 2006-2017. doi:10.1016/S0140-6736(20) 32340-0

Collison, J. (2018). ER Stress Causes Osteoclastogenesis. Nat. Rev. Rheumatol. 14 (4), 184. doi:10.1038/nrrheum.2018.24

Deegan, S., Saveljeva, S., Gorman, A. M., and Samali, A. (2013). Stressinduced Self-Cannibalism: on the Regulation of Autophagy by Endoplasmic Reticulum Stress. Cell. Mol. Life Sci. 70 (14), 2425-2441. doi:10.1007/s00018-012-1173-4

Desmoulin, G. T., Pradhan, V., and Milner, T. E. (2020). Mechanical Aspects of Intervertebral Disc Injury and Implications on Biomechanics. Spine (Phila Pa 1976) 45, E457-E464. doi:10.1097/BRS.0000000000003291

Diseases, G. B. D., and Injuries, C. (2020). Global burden of 369 Diseases and Injuries in 204 Countries and Territories, 1990-2019: a Systematic Analysis for the Global Burden of Disease Study 2019. Lancet 396 (10258), 1204-1222. doi:10.1016/S0140-6736(20)30925-9

Dudek, M., Yang, N., Ruckshanthi, J. P., Williams, J., Borysiewicz, E., Wang, P., et al. (2017). The Intervertebral Disc Contains Intrinsic Circadian Clocks that Are Regulated by Age and Cytokines and Linked to Degeneration. Ann. Rheum. Dis. 76 (3), 576-584. doi:10.1136/annrheumdis-2016-209428

DuRose, J. B., Tam, A. B., and Niwa, M. (2006). Intrinsic Capacities of Molecular Sensors of the Unfolded Protein Response to Sense Alternate Forms of Endoplasmic Reticulum Stress. Mol. Biol. Cel 17 (7), 3095-3107. doi:10.1091/mbc.e06-01-0055

Fass, D. (2019). Going for the Golgi: Small PDI Protein Helps ATF 6 Perform Better under Stress. EMBO J. 38 (15), e102743. doi:10.15252/embj.2019102743

Feng, Y.-x., Sokol, E. S., Del Vecchio, C. A., Sanduja, S., Claessen, J. H. L., Proia, T. A., et al. (2014). Epithelial-to-Mesenchymal Transition Activates PERK-eIF2a and Sensitizes Cells to Endoplasmic Reticulum Stress. Cancer Discov. 4 (6), 702-715. doi:10.1158/2159-8290.CD-13-0945

Fujii, T., Fujita, N., Suzuki, S., Tsuji, T., Takaki, T., Umezawa, K., et al. (2018). The Unfolded Protein Response Mediated by PERK Is Casually Related to the Pathogenesis of Intervertebral Disc Degeneration. J. Orthop. Res. 36 (5), 1334-1345. doi:10.1002/jor.23787

Gardner, B. M., Pincus, D., Gotthardt, K., Gallagher, C. M., and Walter, P. (2013). Endoplasmic Reticulum Stress Sensing in the Unfolded Protein Response. Cold Spring Harbor Perspect. Biol. 5 (3), a013169. doi:10.1101/ cshperspect.a013169

Gautieri, A., Redaelli, A., Buehler, M. J., and Vesentini, S. (2014). Age- and Diabetes-Related Nonenzymatic Crosslinks in Collagen Fibrils: Candidate Amino Acids Involved in Advanced Glycation End-Products. Matrix Biol. 34, 89-95. doi:10.1016/j.matbio.2013.09.004

Ghosh, R., Colon-Negron, K., and Papa, F. R. (2019). Endoplasmic Reticulum Stress, Degeneration of Pancreatic Islet $\beta$-cells, and Therapeutic Modulation of the Unfolded Protein Response in Diabetes. Mol. Metab. 27, S60-S68. doi:10.1016/j.molmet.2019.06.012

Glembotski, C. C., Rosarda, J. D., and Wiseman, R. L. (2019). Proteostasis and beyond: ATF6 in Ischemic Disease. Trends Mol. Med. 25 (6), 538-550. doi:10.1016/j.molmed.2019.03.005

Gopal, D., Ho, A. L., Shah, A., and Chi, J. H. (2012). Molecular Basis of Intervertebral Disc Degeneration. Adv. Exp. Med. Biol. 760, 114-133. doi:10.1007/978-1-4614-4090-1_8

Han, J., Back, S. H., Hur, J., Lin, Y.-H., Gildersleeve, R., Shan, J., et al. (2013). ERstress-induced Transcriptional Regulation Increases Protein Synthesis Leading to Cell Death. Nat. Cel Biol 15 (5), 481-490. doi:10.1038/ncb2738

Harding, H. P., Novoa, I., Zhang, Y., Zeng, H., Wek, R., Schapira, M., et al. (2000). Regulated Translation Initiation Controls Stress-Induced Gene Expression in Mammalian Cells. Mol. Cel 6 (5), 1099-1108. doi:10.1016/s1097-2765(00) 00108-8

Hazari, Y., Bravo-San Pedro, J. M., Hetz, C., Galluzzi, L., and Kroemer, G. (2020). Autophagy in Hepatic Adaptation to Stress. J. Hepatol. 72 (1), 183-196. doi:10.1016/j.jhep.2019.08.026 
Hetz, C., Axten, J. M., and Patterson, J. B. (2019). Publisher Correction: Pharmacological Targeting of the Unfolded Protein Response for Disease Intervention. Nat. Chem. Biol. 15 (11), 1129. doi:10.1038/s41589-019-0363-x

Hetz, C., and Saxena, S. (2017). ER Stress and the Unfolded Protein Response in Neurodegeneration. Nat. Rev. Neurol. 13 (8), 477-491. doi:10.1038/ nrneurol.2017.99

Hetz, C. (2012). The Unfolded Protein Response: Controlling Cell Fate Decisions under ER Stress and beyond. Nat. Rev. Mol. Cel Biol 13 (2), 89-102. doi:10.1038/nrm3270

Hofmann, C., Katus, H. A., and Doroudgar, S. (2019). Protein Misfolding in Cardiac Disease. Circulation 139 (18), 2085-2088. doi:10.1161/ CIRCULATIONAHA.118.037417

Hosseinzadeh, A., Kamrava, S. K., Joghataei, M. T., Darabi, R., Shakeri-Zadeh, A., Shahriari, M., et al. (2016). Apoptosis Signaling Pathways in Osteoarthritis and Possible Protective Role of Melatonin. J. Pineal Res. 61 (4), 411-425. doi:10.1111/jpi.12362

Huang, S., Xing, Y., and Liu, Y. (2019). Emerging Roles for the ER Stress Sensor IRE1a in Metabolic Regulation and Disease. J. Biol. Chem. 294 (49), 18726-18741. doi:10.1074/jbc.REV119.007036

Inoue, N., and Espinoza Orías, A. A. (2011). Biomechanics of Intervertebral Disk Degeneration. Orthop. Clin. North America 42 (4), 487-499. vii. doi:10.1016/ j.ocl.2011.07.001

Ji, T., Zhang, X., Xin, Z., Xu, B., Jin, Z., Wu, J., et al. (2020). Does Perturbation in the Mitochondrial Protein Folding Pave the Way for Neurodegeneration Diseases? Ageing Res. Rev. 57, 100997. doi:10.1016/j.arr.2019.100997

Keestra-Gounder, A. M., Byndloss, M. X., Seyffert, N., Young, B. M., ChávezArroyo, A., Tsai, A. Y., et al. (2016). NOD1 and NOD2 Signalling Links ER Stress with Inflammation. Nature 532 (7599), 394-397. doi:10.1038/ nature17631

Kepler, C. K., Ponnappan, R. K., Tannoury, C. A., Risbud, M. V., and Anderson, D. G. (2013). The Molecular Basis of Intervertebral Disc Degeneration. Spine J. 13 (3), 318-330. doi:10.1016/j.spinee.2012.12.003

Kirkham, B., Chaabo, K., Hall, C., Garrood, T., Mant, T., Allen, E., et al. (2016). Safety and Patient Response as Indicated by Biomarker Changes to Binding Immunoglobulin Protein in the Phase I/IIA RAGULA Clinical Trial in Rheumatoid Arthritis. Rheumatology 55 (11), 1993-2000. doi:10.1093/ rheumatology/kew287

Kitis, S., Coskun, Z. M., Tasdemir, P., Tuncez, E., Zamani, A. G., and Acar, A. (2018). Analysis of Genetic Polymorphisms Associated with Intervertebral Disc Degeneration. Cel Mol Biol (Noisy-le-grand) 64 (10), 61-65. doi:10.14715/cmb/ 2018.64.10.10

Koopman, M., Hetz, C., and Nollen, E. A. A. (2019). Saved by the Matrix: UPR Independent Survival under ER Stress. Cell 179 (6), 1246-1248. doi:10.1016/ j.cell.2019.11.012

Kopp, M. C., Larburu, N., Durairaj, V., Adams, C. J., and Ali, M. M. U. (2019). UPR Proteins IRE1 and PERK Switch BiP from Chaperone to ER Stress Sensor. Nat. Struct. Mol. Biol. 26 (11), 1053-1062. doi:10.1038/s41594-019-0324-9

Krupkova, O., Sadowska, A., Kameda, T., Hitzl, W., Hausmann, O. N., Klasen, J., et al. (2018). p38 MAPK Facilitates Crosstalk between Endoplasmic Reticulum Stress and IL-6 Release in the Intervertebral Disc. Front. Immunol. 9, 1706. doi:10.3389/fimmu.2018.01706

Kustermann, M., Manta, L., Paone, C., Kustermann, J., Lausser, L., Wiesner, C., et al. (2018). Loss of the Novel Vcp (Valosin Containing Protein) Interactor Washc4 Interferes with Autophagy-Mediated Proteostasis in Striated Muscle and Leads to Myopathy In Vivo. Autophagy 14 (11), 1911-1927. doi:10.1080/ 15548627.2018.1491491

Li, H., Li, D., Ma, Z., Qian, Z., Kang, X., Jin, X., et al. (2018). Defective Autophagy in Osteoblasts Induces Endoplasmic Reticulum Stress and Causes Remarkable Bone Loss. Autophagy 14 (10), 1726-1741. doi:10.1080/15548627.2018.1483807

Li, X.-f., Leng, P., Zhang, Z., and Zhang, H.-n. (2017). RETRACTED: The Piezo1 Protein Ion Channel Functions in Human Nucleus Pulposus Cell Apoptosis by Regulating Mitochondrial Dysfunction and the Endoplasmic Reticulum Stress Signal Pathway. Exp. Cel Res. 358 (2), 377-389. doi:10.1016/j.yexcr.2017.07.010

Liao, Z., Luo, R., Li, G., Song, Y., Zhan, S., Zhao, K., et al. (2019). Exosomes from Mesenchymal Stem Cells Modulate Endoplasmic Reticulum Stress to Protect against Nucleus Pulposus Cell Death and Ameliorate Intervertebral Disc Degeneration In Vivo. Theranostics 9 (14), 4084-4100. doi:10.7150/thno.33638

Lin, H., Peng, Y., Li, J., Wang, Z., Chen, S., Qing, X., et al. (2021). Reactive Oxygen Species Regulate Endoplasmic Reticulum Stress and ER-Mitochondrial Ca2+
Crosstalk to Promote Programmed Necrosis of Rat Nucleus Pulposus Cells under Compression. Oxidative Med. Cell Longevity 2021, 1-20. doi:10.1155/ $2021 / 8810698$

Liu, C., Yan, D.-Y., Wang, C., Ma, Z., Deng, Y., Liu, W., et al. (2020). IRE1 Signaling Pathway Mediates Protective Autophagic Response against ManganeseInduced Neuronal Apoptosis In Vivo and In Vitro. Sci. Total Environ. 712, 136480. doi:10.1016/j.scitotenv.2019.136480

Luo, R., Liao, Z., Song, Y., Yin, H., Zhan, S., Li, G., et al. (2019a). Berberine Ameliorates Oxidative Stress-Induced Apoptosis by Modulating ER Stress and Autophagy in Human Nucleus Pulposus Cells. Life Sci. 228, 85-97. doi:10.1016/ j.lfs.2019.04.064

Luo, R., Song, Y., Liao, Z., Yin, H., Zhan, S., Wang, K., et al. (2019b). Impaired Calcium Homeostasis via Advanced Glycation End Products Promotes Apoptosis through Endoplasmic Reticulum Stress in Human Nucleus Pulposus Cells and Exacerbates Intervertebral Disc Degeneration in Rats. FEBS J. 286, 4356-4373. doi:10.1111/febs.14972

Luoma, K., Riihimäki, H., Luukkonen, R., Raininko, R., Viikari-Juntura, E., and Lamminen, A. (2000). Low Back Pain in Relation to Lumbar Disc Degeneration. Spine 25 (4), 487-492. doi:10.1097/00007632-200002150-00016

Luoma, K., Vehmas, T., Kerttula, L., Grönblad, M., and Rinne, E. (2016). Chronic Low Back Pain in Relation to Modic Changes, Bony Endplate Lesions, and Disc Degeneration in a Prospective MRI Study. Eur. Spine J. 25 (9), 2873-2881. doi:10.1007/s00586-016-4715-x

Ma, C.-J., Liu, X., Che, L., Liu, Z.-H., Samartzis, D., and Wang, H.-Q. (2015). Stem Cell Therapies for Intervertebral Disc Degeneration: Immune Privilege Reinforcement by Fas/FasL Regulating Machinery. Cscr 10 (4), 285-295. doi:10.2174/1574888x10666150416114027

Ma, K.-G., Shao, Z.-W., Yang, S.-H., Wang, J., Wang, B.-C., Xiong, L.-M., et al. (2013). Autophagy Is Activated in Compression-Induced Cell Degeneration and Is Mediated by Reactive Oxygen Species in Nucleus Pulposus Cells Exposed to Compression. Osteoarthritis and Cartilage 21 (12), 2030-2038. doi:10.1016/ j.joca.2013.10.002

Maiuolo, J., Bulotta, S., Verderio, C., Benfante, R., and Borgese, N. (2011). Selective Activation of the Transcription Factor ATF6 Mediates Endoplasmic Reticulum Proliferation Triggered by a Membrane Protein. Proc. Natl. Acad. Sci. 108 (19), 7832-7837. doi:10.1073/pnas.1101379108

Malhi, H., and Kaufman, R. J. (2011). Endoplasmic Reticulum Stress in Liver Disease. J. Hepatol. 54 (4), 795-809. doi:10.1016/j.jhep.2010.11.005

Marciniak, S. J., Yun, C. Y., Oyadomari, S., Novoa, I., Zhang, Y., Jungreis, R., et al. (2004). CHOP Induces Death by Promoting Protein Synthesis and Oxidation in the Stressed Endoplasmic Reticulum. Genes Dev. 18 (24), 3066-3077. doi:10.1101/gad.1250704

Maurel, M., Chevet, E., Tavernier, J., and Gerlo, S. (2014). Getting RIDD of RNA: IRE1 in Cell Fate Regulation. Trends Biochem. Sci. 39 (5), 245-254. doi:10.1016/ j.tibs.2014.02.008

Meroni, R., Piscitelli, D., Ravasio, C., Vanti, C., Bertozzi, L., De Vito, G., et al. (2021). Evidence for Managing Chronic Low Back Pain in Primary Care: a Review of Recommendations from High-Quality Clinical Practice Guidelines. Disabil. Rehabil. 43 (7), 1029-1043. doi:10.1080/09638288.2019.1645888

Mogilenko, D. A., Haas, J. T., L'homme, L., Fleury, S., Quemener, S., Levavasseur, M., et al. (2019). Metabolic and Innate Immune Cues Merge into a Specific Inflammatory Response via the UPR. Cell 177 (5), 1201-1216. e1219. doi:10.1016/j.cell.2019.03.018

Mullan, L. A., Mularczyk, E. J., Kung, L. H., Forouhan, M., Wragg, J. M. A., Goodacre, R., et al. (2017). Increased Intracellular Proteolysis Reduces Disease Severity in an ER Stress-Associated Dwarfism. J. Clin. Invest. 127 (10), 3861-3865. doi:10.1172/JCI93094

Naiel, S., Tat, V., Padwal, M., Vierhout, M., Mekhael, O., Yousof, T., et al. (2020). Protein Misfolding and Endoplasmic Reticulum Stress in Chronic Lung Disease. Chest 157, 1207-1220. doi:10.1016/j.chest.2019.11.009

O'Keeffe, M., Maher, C. G., Rozbroj, T., Schoene, M., and Buchbinder, R. (2020). Lessons from the Lancet Low Back Pain Series media Strategy. The Lancet 396 (10262), 1560-1561. doi:10.1016/S0140-6736(20)32325-4

Ochoa, C. D., Wu, R. F., and Terada, L. S. (2018). ROS Signaling and ER Stress in Cardiovascular Disease. Mol. Aspects Med. 63, 18-29. doi:10.1016/ j.mam.2018.03.002

Oka, O. B., Lith, M., Rudolf, J., Tungkum, W., Pringle, M. A., and Bulleid, N. J. (2019). ER P18 Regulates Activation of ATF 6a during Unfolded Protein Response. EMBO J. 38 (15), e100990. doi:10.15252/embj.2018100990 
Pattappa, G., Li, Z., Peroglio, M., Wismer, N., Alini, M., and Grad, S. (2012). Diversity of Intervertebral Disc Cells: Phenotype and Function. J. Anat. 221 (6), 480-496. doi:10.1111/j.1469-7580.2012.01521.x

Pedersen, S. J., and Maksymowych, W. P. (2019). The Pathogenesis of Ankylosing Spondylitis: an Update. Curr. Rheumatol. Rep. 21 (10), 58. doi:10.1007/s11926019-0856-3

Preissler, S., and Ron, D. (2019). Early Events in the Endoplasmic Reticulum Unfolded Protein Response. Cold Spring Harb Perspect. Biol. 11 (4), a033894. doi:10.1101/cshperspect.a033894

Rahmati, M., Moosavi, M. A., and McDermott, M. F. (2018). ER Stress: A Therapeutic Target in Rheumatoid Arthritis? Trends Pharmacol. Sci. 39 (7), 610-623. doi:10.1016/j.tips.2018.03.010

Raj, P. P. (2008). Intervertebral Disc: Anatomy-Physiology-PathophysiologyTreatment. Pain Pract. 8 (1), 18-44. doi:10.1111/j.1533-2500.2007.00171.x

Reibe, S., and Febbraio, M. A. (2019). Relieving ER Stress to Target NASH-Driven Hepatocellular Carcinoma. Nat. Rev. Endocrinol. 15 (2), 73-74. doi:10.1038/ s41574-018-0145-7

Rojas-Rivera, D., Delvaeye, T., Roelandt, R., Nerinckx, W., Augustyns, K., Vandenabeele, P., et al. (2017). When PERK Inhibitors Turn Out to Be New Potent RIPK1 Inhibitors: Critical Issues on the Specificity and Use of GSK2606414 and GSK2656157. Cell Death Differ 24 (6), 1100-1110. doi:10.1038/cdd.2017.58

Roughley, P. J., Melching, L. I., Heathfield, T. F., Pearce, R. H., and Mort, J. S. (2006). The Structure and Degradation of Aggrecan in Human Intervertebral Disc. Eur. Spine J. 15 (Suppl. 3), 326-332. doi:10.1007/s00586-006-0127-7

Savic, S., Ouboussad, L., Dickie, L. J., Geiler, J., Wong, C., Doody, G. M., et al. (2014). TLR Dependent XBP-1 Activation Induces an Autocrine Loop in Rheumatoid Arthritis Synoviocytes. J. Autoimmun. 50, 59-66. doi:10.1016/ j.jaut.2013.11.002

Senft, D., and Ronai, Z. e. A. (2015). UPR, Autophagy, and Mitochondria Crosstalk Underlies the ER Stress Response. Trends Biochem. Sci. 40 (3), 141-148. doi:10.1016/j.tibs.2015.01.002

Shi, M., Zhao, Y., Sun, Y., Xin, D., Xu, W., and Zhou, B. (2021). Therapeutic Effect of Co-culture of Rat Bone Marrow Mesenchymal Stem Cells and Degenerated Nucleus Pulposus Cells on Intervertebral Disc Degeneration. Spine J. 21 (9), 1567-1579. doi:10.1016/j.spinee.2021.05.007

Shoulders, M. D., Ryno, L. M., Genereux, J. C., Moresco, J. J., Tu, P. G., Wu, C., et al. (2013). Stress-Independent Activation of XBP1s And/or ATF6 Reveals Three Functionally Diverse ER Proteostasis Environments. Cell Rep. 3 (4), 1279-1292. doi:10.1016/j.celrep.2013.03.024

Shpilka, T., and Haynes, C. M. (2018). The Mitochondrial UPR: Mechanisms, Physiological Functions and Implications in Ageing. Nat. Rev. Mol. Cel Biol 19 (2), 109-120. doi:10.1038/nrm.2017.110

Siwecka, N., Rozpędek, W., Pytel, D., Wawrzynkiewicz, A., Dziki, A., Dziki, Ł., et al. (2019). Dual Role of Endoplasmic Reticulum Stress-Mediated Unfolded Protein Response Signaling Pathway in Carcinogenesis. Int. J. Mol. Sci. 20 (18), 4354. doi:10.3390/ijms20184354

St-Pierre, J., Buckingham, J. A., Roebuck, S. J., and Brand, M. D. (2002). Topology of Superoxide Production from Different Sites in the Mitochondrial Electron Transport Chain. J. Biol. Chem. 277 (47), 44784-44790. doi:10.1074/ jbc.M207217200

Sullivan, G. P., O'Connor, H., Henry, C. M., Davidovich, P., Clancy, D. M., Albert, M. L., et al. (2020). TRAIL Receptors Serve as Stress-Associated Molecular Patterns to Promote ER-Stress-Induced Inflammation. Develop. Cel 52 (6), 714-730. e715. doi:10.1016/j.devcel.2020.01.031

Tang, Q., Zheng, G., Feng, Z., Chen, Y., Lou, Y., Wang, C., et al. (2017). Trehalose Ameliorates Oxidative Stress-Mediated Mitochondrial Dysfunction and ER Stress via Selective Autophagy Stimulation and Autophagic Flux Restoration in Osteoarthritis Development. Cel Death Dis 8 (10)-e3081. doi:10.1038/ cddis. 2017.453

Taylor, S., and Bishop, A. (2020). Patient and Public Beliefs about the Role of Imaging in the Management of Non-specific Low Back Pain: a Scoping Review. Physiotherapy 107, 224-233. doi:10.1016/j.physio.2019.08.014

Urban, J. P. G., Smith, S., and Fairbank, J. C. T. (2004). Nutrition of the Intervertebral Disc. Spine 29 (23), 2700-2709. doi:10.1097/ 01.brs.0000146499.97948.52

Urits, I., Burshtein, A., Sharma, M., Testa, L., Gold, P. A., Orhurhu, V., et al. (2019). Low Back Pain, a Comprehensive Review: Pathophysiology, Diagnosis, and
Treatment. Curr. Pain Headache Rep. 23 (3), 23. doi:10.1007/s11916-0190757-1

van den Berg, R., Jongbloed, L. M., Kuchuk, N. O., Roorda, L. D., Oostveen, J. C. M., Koes, B. W., et al. (2017). The Association between Self-Reported Low Back Pain and Radiographic Lumbar Disc Degeneration of the Cohort Hip and Cohort Knee (CHECK) Study. Spine (Phila Pa 1976) 42 (19), 1464-1471. doi:10.1097/BRS.0000000000002228

Vergroesen, P.-P. A., Kingma, I., Emanuel, K. S., Hoogendoorn, R. J. W., Welting, T. J., van Royen, B. J., et al. (2015). Mechanics and Biology in Intervertebral Disc Degeneration: a Vicious circle. Osteoarthritis and Cartilage 23 (7), 1057-1070. doi:10.1016/j.joca.2015.03.028

Von Forell, G. A., Stephens, T. K., Samartzis, D., and Bowden, A. E. (2015). Low Back Pain. Spine 40 (15), 1165-1172. doi:10.1097/BRS.0000000000000982

Waldherr, S. M., Strovas, T. J., Vadset, T. A., Liachko, N. F., and Kraemer, B. C. (2019). Constitutive XBP-1s-Mediated Activation of the Endoplasmic Reticulum Unfolded Protein Response Protects against Pathological Tau. Nat. Commun. 10 (1), 4443. doi:10.1038/s41467-019-12070-3

Walter, P., and Ron, D. (2011). The Unfolded Protein Response: from Stress Pathway to Homeostatic Regulation. Science 334 (6059), 1081-1086. doi:10.1126/science.1209038

Wang, B., Ke, W., Wang, K., Li, G., Ma, L., Lu, S., et al. (2021). Mechanosensitive Ion Channel Piezol Activated by Matrix Stiffness Regulates Oxidative StressInduced Senescence and Apoptosis in Human Intervertebral Disc Degeneration. Oxidative Med. Cell Longevity 2021, 1-13. doi:10.1155/2021/ 8884922

Wang, D., He, X., Wang, D., Peng, P., Xu, X., Gao, B., et al. (2020). Quercetin Suppresses Apoptosis and Attenuates Intervertebral Disc Degeneration via the SIRT1-Autophagy Pathway. Front. Cel Dev. Biol. 8, 613006. doi:10.3389/ fcell.2020.613006

Wang, J., Yang, X., and Zhang, J. (2016). Bridges between Mitochondrial Oxidative Stress, ER Stress and mTOR Signaling in Pancreatic $\beta$ Cells. Cell Signal. 28 (8), 1099-1104. doi:10.1016/j.cellsig.2016.05.007

Wang, W., Qing, X., Wang, B., Ma, K., Wei, Y., and Shao, Z. (2018). Tauroursodeoxycholic Acid Protects Nucleus Pulposus Cells from CompressionInduced Apoptosis and Necroptosis via Inhibiting Endoplasmic Reticulum Stress. Evidence-Based Complement. Altern. Med. 2018, 1-11. doi:10.1155/2018/6719460

Welch, W. J., and Brown, C. R. (1996). Influence of Molecular and Chemical Chaperones on Protein Folding. Cell Stress Chaper 1 (2), 109-115. doi:10.1379/ 1466-1268(1996)001<0109:iomacc>2.3.co;2

Wen, T., Xue, P., Ying, J., Cheng, S., Liu, Y., and Ruan, D. (2021). The Role of Unfolded Protein Response in Human Intervertebral Disc Degeneration: Perk and IRE1- $\alpha$ as Two Potential Therapeutic Targets. Oxidative Med. Cell Longevity 2021, 1-9. doi:10.1155/2021/6492879

Woo, C. W., Cui, D., Arellano, J., Dorweiler, B., Harding, H., Fitzgerald, K. A., et al. (2009). Adaptive Suppression of the ATF4-CHOP branch of the Unfolded Protein Response by Toll-like Receptor Signalling. Nat. Cel Biol 11 (12), 1473-1480. doi:10.1038/ncb1996

Woodman, I. (2013). HLA-B27-induced ER Stress Might Promote Bone Loss in SpA. Nat. Rev. Rheumatol. 9 (7), 383. doi:10.1038/nrrheum.2013.80

Wozniak, A. L., Wang, X., Stieren, E. S., Scarbrough, S. G., Elferink, C. J., and Boehning, D. (2006). Requirement Of Biphasic Calcium Release From The Endoplasmic Reticulum For Fas-Mediated Apoptosis. J. Cell Biol. 175 (5), 709-714. doi:10.1083/jcb.200608035

Wu, H., Carvalho, P., and Voeltz, G. K. (2018). Here, There, and Everywhere: The Importance of ER Membrane Contact Sites. Science 361 (6401). doi:10.1126/ science.aan 5835

Wu, W., Zhang, X., Hu, X., Wang, X., Sun, L., Zheng, X., et al. (2014). Lactate Down-Regulates Matrix Systhesis and Promotes Apoptosis and Autophagy in Rat Nucleus Pulposus Cells. J. Orthop. Res. 32 (2), 253-261. doi:10.1002/ jor.22503

Xie, L., Chen, Z., Liu, M., Huang, W., Zou, F., Ma, X., et al. (2020). MSC-derived Exosomes Protect Vertebral Endplate Chondrocytes against Apoptosis and Calcification via the miR-31-5p/ATF6 Axis. Mol. Ther. - Nucleic Acids 22, 601-614. doi:10.1016/j.omtn.2020.09.026

Xie, Q., Khaoustov, V. I., Chung, C. C., Sohn, J., Krishnan, B., Lewis, D. E., et al. (2002). Effect of Tauroursodeoxycholic Acid on Endoplasmic Reticulum StressInduced Caspase-12 Activation. Hepatology 36 (3), 592-601. doi:10.1053/ jhep.2002.35441 
Xie, Z.-Y., Chen, L., Wang, F., Liu, L., Zhang, C., Wang, K., et al. (2017). Endoplasmic Reticulum Stress Is Involved in Nucleus Pulposus Degeneration and Attenuates Low pH-Induced Apoptosis of Rat Nucleus Pulposus Cells. DNA Cel Biol. 36 (8), 627-637. doi:10.1089/dna.2017.3736

Xie, Z.-Y., Chen, L., Zhang, C., Liu, L., Wang, F., Cai, F., et al. (2018). Acid-Sensing Ion Channel 1a Regulates Fate of Rat Nucleus Pulposus Cells in Acid Stimulus through Endoplasmic Reticulum Stress. BioResearch Open Access 7 (1), 2-9. doi:10.1089/biores.2017.0049

Xu, D., Jin, H., Wen, J., Chen, J., Chen, D., Cai, N., et al. (2017). Hydrogen Sulfide Protects against Endoplasmic Reticulum Stress and Mitochondrial Injury in Nucleus Pulposus Cells and Ameliorates Intervertebral Disc Degeneration. Pharmacol. Res. 117, 357-369. doi:10.1016/j.phrs.2017.01.005

Xu, X., Wang, D., Zheng, C., Gao, B., Fan, J., Cheng, P., et al. (2019). Progerin Accumulation in Nucleus Pulposus Cells Impairs Mitochondrial Function and Induces Intervertebral Disc Degeneration and Therapeutic Effects of Sulforaphane. Theranostics 9 (8), 2252-2267. doi:10.7150/thno.30658

Yang, H., Wen, Y., Zhang, M., Liu, Q., Zhang, H., Zhang, J., et al. (2020a). MTORC1 Coordinates the Autophagy and Apoptosis Signaling in Articular Chondrocytes in Osteoarthritic Temporomandibular Joint. Autophagy 16 (2), 271-288. doi:10.1080/15548627.2019.1606647

Yang, Y., Zhou, Q., Gao, A., Chen, L., and Li, L. (2020b). Endoplasmic Reticulum Stress and Focused Drug Discovery in Cardiovascular Disease. Clinica Chim. Acta 504, 125-137. doi:10.1016/j.cca.2020.01.031

Yoo, S.-A., You, S., Yoon, H.-J., Kim, D.-H., Kim, H.-S., Lee, K., et al. (2012). A Novel Pathogenic Role of the ER Chaperone GRP78/BiP in Rheumatoid Arthritis. J. Exp. Med. 209 (4), 871-886. doi:10.1084/jem.20111783

Zhang, Y.-H., Zhao, C.-Q., Jiang, L.-S., and Dai, L.-Y. (2011). Lentiviral shRNA Silencing of CHOP Inhibits Apoptosis Induced by Cyclic Stretch in Rat Annular Cells and Attenuates Disc Degeneration in the Rats. Apoptosis 16 (6), 594-605. doi:10.1007/s10495-011-0596-y

Zhang, Z., Lin, J., Nisar, M., Chen, T., Xu, T., Zheng, G., et al. (2019a). The Sirt1/ P53 Axis in Diabetic Intervertebral Disc Degeneration Pathogenesis and Therapeutics. Oxidative Med. Cell Longevity 2019, 1-21. doi:10.1155/2019/ 7959573
Zhang, Z., Lin, J., Tian, N., Wu, Y., Zhou, Y., Wang, C., et al. (2019b). Melatonin Protects Vertebral Endplate Chondrocytes against Apoptosis and Calcification via the Sirt1-Autophagy Pathway. J. Cel Mol Med 23 (1), 177-193. doi:10.1111/ jcmm.13903

Zhao, C.-Q., Zhang, Y.-H., Jiang, S.-D., Jiang, L.-S., and Dai, L.-Y. (2010). Both endoplasmic Reticulum and Mitochondria Are Involved in Disc Cell Apoptosis and Intervertebral Disc Degeneration in Rats. Age 32 (2), 161-177. doi:10.1007/ s11357-009-9121-4

Zhao, Q., Zhou, H., Chi, S., Wang, Y., Wang, J., Geng, J., et al. (2018). Structure and Mechanogating Mechanism of the Piezol Channel. Nature 554 (7693), 487-492. doi:10.1038/nature25743

Zheng, C.-J., and Chen, J. (2015). Disc Degeneration Implies Low Back Pain. Theor. Biol. Med. Model. 12, 24. doi:10.1186/s12976-015-0020-3

Zheng, C., Lin, X., Xu, X., Wang, C., Zhou, J., Gao, B., et al. (2019). Suppressing UPRdependent Overactivation of FGFR3 Signaling Ameliorates SLC26A2-Deficient Chondrodysplasias. EBioMedicine 40, 695-709. doi:10.1016/j.ebiom.2019.01.010

Conflict of Interest: The authors declare that the research was conducted in the absence of any commercial or financial relationships that could be construed as a potential conflict of interest.

Publisher's Note: All claims expressed in this article are solely those of the authors and do not necessarily represent those of their affiliated organizations, or those of the publisher, the editors and the reviewers. Any product that may be evaluated in this article, or claim that may be made by its manufacturer, is not guaranteed or endorsed by the publisher.

Copyright (c) 2022 Wang, He, Zheng, Wang, Peng, Gao, Xu, Ma, Liu, Yang and Luo. This is an open-access article distributed under the terms of the Creative Commons Attribution License (CC BY). The use, distribution or reproduction in other forums is permitted, provided the original author(s) and the copyright owner(s) are credited and that the original publication in this journal is cited, in accordance with accepted academic practice. No use, distribution or reproduction is permitted which does not comply with these terms. 